\title{
Research on the Influencing Factors of Learning Effect of Online Courses in Higher Education
}

\begin{abstract}
Cancan $\mathrm{Li}^{*}$
Zhejiang Gongshang University, China

${ }^{*}$ Corresponding author. Email: 18989460573@163.com

ABSTRACT

"Online course" uses information technology to integrate and allocate course resources, time and space, and guides teachers and students to carry out online teaching activities. Since the outbreak began, the Chinese government has adopted the policy of "no suspension of classes". How is the learning effect of online courses developed so rapidly? Based on the theory of interactive influence distance and related literature review, this study constructed a model of influencing factors for learning effect of online courses in higher education. Based on a survey of 766 students' online courses, multiple regression analysis was carried out to explore the factors influencing the learning effect and countermeasures. The results show that the content utility, interaction utility and student autonomy of online courses in higher education have a positive and significant effect on the learning effect, in which course satisfaction evaluation plays a mediating role. The content, interaction and autonomy of mixed teaching mode (live broadcast + video broadcast) have a more positive effect on the course satisfaction evaluation. The course satisfaction of the students with choleric temperament has a more positive influence on the learning effect. In this regard, from the course design and student incentive point of view to put forward reasonable suggestions.
\end{abstract}

Keywords: Online course, Interactive influence distance theory, Social interaction, Learning autonomy, Temperament type.

\section{INTRODUCTION}

In the context of "Internet + ", online education is nothing new. Network construction and technological change of mobile intelligent devices accelerate the transformation of online, intelligent and information technology in education. Online learning and blended learning have increased in quantity and quality (Allen and Seaman, 2016), and interaction between students and teachers is no longer limited to face-to-face forms. "Online course" adopts information technology to integrate and allocate course resources, time and space to guide teachers and students to carry out online teaching activities, which plays a positive role in deepening education and teaching reform.

However, controversies regarding the effectiveness of online courses continue (Huang Lu, 2020), and some scholars believe that the teaching model of the duplicating schools lacks innovation (Jon Bagley and Xiao Junhong, 2017). Since the outbreak began, the Chinese government has adopted the policy of "no suspension of classes", creating a new starting point for global teaching innovation and comprehensively promoting the popularization of the online course education model. According to the China Education and Research Computer Network, as of June 2020, the number of online education users in China had reached 381 million. In the first half of 2020, under the guidance and help of the policy of "no suspension of classes", 282 million students nationwide switched to online courses, further improving the level of education informatization. On March 23, 2020, in order to understand the current situation of education effect during the epidemic, Zhejiang Consumer Protection Commission found that the first factor that parents consider when choosing online platforms for their children is teaching effect, accounting for $66.67 \%$, followed by teachers, accounting for $55.11 \%$, and the overall satisfaction of online courses is $61.29 \%$ (China Youth Network, 2020). With the rapid development of online courses, people begin to pay attention to these issues: First, how effective is the learning of online courses? Second, what are the factors that affect the learning effect of students' online courses? Do the course features have obvious advantages? Third, are the learning outcomes of students participating in online courses related to their own characteristics, and what are the connections? 
The research of online courses in higher education is mainly focused on the construction of online courses, but there are few researches on the effectiveness of online courses, especially on the learning effect and learning behavior of students. Therefore, this study will also focus on the factors that affect the learning effect of online courses for college students, and explore the influencing mechanisms such as course characteristics and students' own characteristics.

\section{LITERATURE REVIEW}

\subsection{Theory of Transactional Distance}

The Theory of transactional distance was proposed by the famous American scholar Michael Moore in 1972 (Moore, 1989). Interactive distance is a space that needs to span psychology and communication. Potential misunderstandings will be generated between teachers and learners (Jennifer and Jody, 2018), also known as Moore Theory, which divides distance education into two dimensions of interactive distance (physics) and student autonomy (psychology). The relationship between distance education is explained at three levels: dialogue, structure and autonomy. It puts forward a new perspective for independent learning in distance education, which is conducive to students' autonomy.

In the dimension of interactive distance, Moore pointed out that the interaction between students and content and between students and teachers should span the physical dimension to realize online learning. The interaction distance between teachers and students is determined by two levels: Dialogue and Structure. Dialogue refers to the degree of communication response between students and teachers in the education system. Interview, video conferencing, social software, electronic materials and other AIDS; Structure refers to the degree to which learners are satisfied by course structure design, course auxiliary materials and teaching content arrangement in the teaching arrangement. In the process of online learning, students' utility evaluation of teaching course material content due to their own differences is adjusted based on individual needs. The second dimension of the interactive impact distance theory is student autonomy, which refers to the degree to which learners, rather than teachers, decide learning goals, learning experiences and evaluation decisions in the teaching-learning relationship (Jennifer and Jody, 2018). In the context of distance education, students' autonomy and attention play an important role.

Moore's theory of interactive influence distance provides a basic framework for the research of distance education. Based on this theory, this study will measure the factors that influence the learning effect of online courses. This theory has a guiding significance for the rationalization and differentiation improvement of online courses.

\subsection{Theoretical Review}

\subsubsection{Utility of Online Course Material Content}

Information-based education emphasizes the dynamism, sustainability and openness of learning resources. Higher education requires students not only to cultivate their professional abilities, but also to cultivate their practical abilities (Weiwei Wang, 2020). Five basic principles based on teaching, each of which is closely related to the utility of the material content of the course. The material content of online course includes teachers, text, audio, image and video, etc. The utility of the material content is closely related to the course satisfaction, thus affecting the learning effect of online course for college students. Studies that online course content quality is to point to to meet the needs of learners in learning and communication, conform to the course content, the Internet media content and characteristics of the network information resource content index (Lu Huang, etc., 2020), from the course of the professional degree, the scarcity of the Internet, the development degree of specification to evaluate the quality of online courses.

H1a: The utility level of the material content of the course has a significant positive influence on the learning effect.

H2a: The evaluation of students' course satisfaction plays a mediating role between the utility of material content and the learning effect.

\subsubsection{Learning Interaction Utility}

Interactive learning is based on real life experiences, involving interaction and communication between teachers and students, as well as between students, and allows students to develop critical thinking. The increased use of social media has contributed to the increased interaction of online courses.

The key to the success of online courses in higher education is meaningful interaction between students and teachers (Baldwinet et al., 2018). According to Moore's interactive influence distance theory (Moore, 1989), distance educators need to agree on at least three types of interaction: student-content interaction, student-teacher interaction, and student-student interaction. The interaction between students and content is a key feature of the success of distance education, which will lead to changes in students' understanding and cognitive structure; The interaction between students and teachers in online education will determine whether teachers' teaching goals can match students' expectations. Teachers will improve students' self-awareness through encouragement. Students interact with each other through the online course, either individually or in small groups. The effectiveness of 
interaction between students depends to a large extent on the learners' environment, experience and level of autonomous learning. For younger learning groups, motivational teaching goals are achieved through peer group interaction (Moore, 1989). In the 21st century, it emphasizes the importance of teachers guiding students in group cooperative learning and communication and the necessity of teachers guiding students in learning. In the relevant research on the learning experience of online courses in higher education, social interaction is divided into two dimensions: teacher-student interaction and peer interaction, and teacher-student interaction includes the interaction between the teacher and the learner in the course.

The selection of appropriate teaching skills is an important factor in the interaction between teachers and students. If teachers have enough control and practical experience, they will be able to fully understand the psychological characteristics of students, thus stimulating the learning effect. In the absence of teacher support, students have limited ability to understand the learning material (Baars et al., 2018), which may have a negative impact on the subsequent learning process, that is, the learning effect of online courses is poor, so the degree of teacher-student interaction is particularly important in online learning.

H1b: The interactive utility level has a significant positive influence on the learning effect. The higher the interactive utility level of online courses is, the higher the learning effect of students will be.

$\mathrm{H} 2 \mathrm{~b}$ : The evaluation of students' course satisfaction plays a mediating role in the relationship between the interaction utility of independent variables and the learning effect.

\subsubsection{Attention}

Previous studies have pointed out that lack of attention will directly lead to lifelong reading and learning problems (Pingault et al., 2011). In Xia Ji et al, during the outbreak of the influencing factors of online learning in dimensions including learning attitude, attendance, learning environment, attention, self-control, operating quality is variable, according to the result of the attention is "closed not suspended" students online learning quality is a competitive level.

H1c: Both attention levels have a significant positive influence on learning effect. The higher students' attention level is, the higher students' learning effect will be.

H2c: The evaluation of students' course satisfaction plays a mediating role in the relationship between independent variable attention and learning outcomes.

\subsubsection{Autonomy}

Holec (1981) points out that learning autonomy is the ability of learners to be responsible for their own learning process, and autonomous learning mainly includes five aspects: setting learning goals, determining learning content and plans, selecting learning methods and skills, monitoring learning process and evaluating learning results (Zhang, 2020). Autonomous learning not only depends on the individual, but also on the learning autonomy of group cultivation (Zhang, 2020). The definitions of learning autonomy in China include competency theory (learners' self-management ability), environmental theory (overcoming environmental interference to achieve goals and tasks), responsibility (learners are responsible for their own behavior results), and comprehensive theory. Online learners with more learning initiative are also more likely to have the control of learning in their own hands. In this paper, the definition of learning autonomy proposed by Holec scholars is adopted to divide the dimension items.

H1d: The level of autonomy has a significant positive influence on learning effect. The higher the level of autonomy of students is, the higher the learning effect of students will be.

H2d: The evaluation of students' course satisfaction plays a mediating role in the relationship between independent variable autonomy and learning effect.

\subsubsection{Temperament Type}

Type of temperament refers to the combination of similar or common psychological traits displayed on a certain kind of people. Helen's research shows that temperament is a stable personality trait, and different individuals show different temperament characteristics. According to these characteristics, temperament can be classified into four basic types: mucous, choleric, depressive and sanguine, and the differences of temperament types can be measured from the dimensions of emotion, behavior and sensibility.

According to the different temperament type, the individual's sensitivity, endurance, attention, responsiveness, agility and so on will have different performance. According to the existing four types of division has the following characteristics (Liang Yuwei and ling yi, 2020) : (1) the phlegmatic: low reaction phase, slow and stable emotion and behavior, unbalance of higher nervous activity, quiet, sedate, taciturn, emotion is not easy to appear, attention stability but difficult to transfer, patience is stronger, behavior and emotion showed batter; (2) Choleric: quick reaction, high reactivity and initiative, rapid and intense emotion and behavior, but not lasting, energetic and enthusiastic but lack of patience, flexible thinking, stable concentration but difficult to shift; (3) depressive quality: 
high sensitivity, slow emotional and behavioral movements, obscure but not exposed and sentimental, rich imagination, high sensitivity, showing the characteristics of timidity, poor communication, with obvious introversion; (4) Sanguine quality: has a very high responsiveness, emotion and behavior happen quickly and change quickly, good at making friends and strong adaptability, expressive language and infectious, have obvious extroverted, but attention and interest is easy to transfer, lack of patience in the aspect of willpower, perseverance is not strong.

H3: Compared with students with mixed personal temperament types, the course satisfaction of students with mucous $\mathrm{H} 3 \mathrm{a}$, choleric $\mathrm{H} 3 \mathrm{~b}$, depressive $\mathrm{H} 3 \mathrm{c}$ and sanguine $\mathrm{H} 3 \mathrm{~d}$ has a significant positive influence on the learning effect.

\subsubsection{Other Studies}

Some scholars have studied the influencing factors of online course learners' satisfaction, including flexibility and quality of online course, perceived usefulness, perceived ease of use, diversification of assessment, etc.. Ozlem (2014) and Yukselturk (2009) found that there was basically no difference in the satisfaction evaluation of students for online courses in terms of age and gender, and the difference analysis of grades and major categories was also negligible (Li Yingying, 2020). There are differences in the evaluation of students on the learning duration and teaching type of online courses in previous studies. Short learning duration leads to high satisfaction but poor learning effect; otherwise, the effect is opposite. In previous studies, scholars have proposed that students are more satisfied with online courses in a mix of live and recorded formats.

H4: Compared with the students who have studied for a short time, the material content utility $\mathrm{H} 4 \mathrm{a}$, interaction utility $\mathrm{H} 4 \mathrm{~b}$, attention $\mathrm{H} 4 \mathrm{c}$ and autonomy $\mathrm{H} 4 \mathrm{~d}$ of online courses have a significant positive impact on course satisfaction for the students who have studied for a long time.

H5: Compared with the single teaching mode of "live broadcasting/recording", for the online course of "live broadcasting + recording", the material content utility $\mathrm{H} 5 \mathrm{a}$, interaction utility $\mathrm{H} 5 \mathrm{~b}$, students' attention $\mathrm{H} 5 \mathrm{cC}$ and autonomy $\mathrm{H} 5 \mathrm{~d}$ have a significant positive influence on course satisfaction.

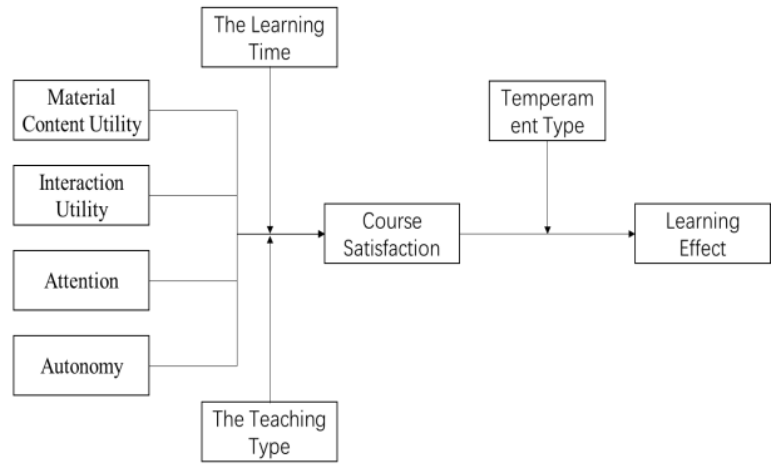

Figure 1. Research model

\section{STUDY DESIGN}

Questionnaire design: The first part is the basic characteristics of the respondents, such as school, major, grade, study duration, teaching type, etc. The second part is the specific survey of online course, including details of online course material, interaction with teachers and students, students' attention, learning effect, course satisfaction, etc., all using Likert5 scale. The third part is the test of autonomy problem. The fourth part is the temperament type test item. The questionnaire includes 79 questions.

Data for this study were collected from the 2020310 solstice, a total of 1014 students who participated in the survey during April 1, 2020.The main subjects of this study are students with online course education experience. The effective sample is 766 , and the effective rate of the questionnaire is $75.54 \%$.

The learning duration was divided into two categories: 638 samples were collected from the longer group (> 120 minutes), and 128 samples were collected from the shorter group ( $<120$ minutes). When coding, the value of $>120$ was 1 , and the value of $<120$ was 0 . There are two types of lectures: the live/recording group has 140 samples, coded as 1; There are 626 samples in the live broadcasting + recording group, and the code is 0 . There were five temperament types: 215 mucous, 41 choleric, 60 depressive, 90 sanguine and 360 mixed. Of the five temperament types, if the subject belongs to this type, the code is 1 , otherwise it is 0 .

\section{DISCUSSION}

\subsection{Reliability and Validity Test}

In order to ensure the internal consistency of the measurement items, the questionnaire data were screened and some items were reverse coded, and then the specific analysis was carried out.

Finally, the reliability and validity test results of the three variables of data content utility, interaction utility and autonomy utility are good. 


\subsection{Analysis on the Influencing Factors of Online Course Learning Effect}

\subsubsection{Main Effect Analysis}

According to the correlation analysis, the Pearson correlation between independent variables and dependent variables is good, among which the correlation coefficient between data content utility and learning effect is the largest ( $\mathrm{r}=0.643)$, interaction utility is significantly positively correlated with learning effect $(\mathrm{r}=0.576)$, and autonomy is significantly positively correlated with learning effect $(\mathrm{r}=0.466)$. Therefore, it can be preliminarily inferred that college students' online course learning behavior will have a higher learning effect when the course material is rich, the interaction between teachers and students is positive, and students have strong autonomy. According to the model summary table, the $\mathrm{R}$ squared of the model is 0.458 , and the $\mathrm{R}$ squared after adjustment is 0.456 . The model has good goodness of fit. The $\mathrm{F}$ value of the model is 214.414, and the significant change level is 0.000 . The results show that the regression equation has passed the validity test. A linear regression relationship exists between independent variables and dependent variables. The effects of the three variables of content utility, interaction utility and autonomy on the learning effect of the dependent variable are all significant at the level of 0.05 , that is, the three independent variables have significant predictive power on the dependent variable, which can explain the variation of the dependent variable of $76.7 \%$. Let's say that $\mathrm{H} 1$ is proven. The multiple linear regression equation obtained is as follows:

$$
\mathrm{Y}=2.296+0.427 \mathrm{X} 1+0.225 \mathrm{X} 2+0.115 \mathrm{X} 3
$$

Where $\mathrm{Y}$ is the dependent variable, representing the learning effect; $\mathrm{X} 1, \mathrm{X} 2$ and $\mathrm{X} 3$ respectively represent the content utility, interaction utility and autonomy of independent variables.

\subsubsection{Analysis on the Moderating Effect of Temperament Type}

According to the literature analysis of models with mediating and moderating variables, the moderated mediating effect test was conducted on the hypothesis model. Students' learning effect was taken as the dependent variable, three variables of material content utility, interaction utility and autonomy were taken as independent variables, students' course satisfaction for online courses was taken as the mediating variable, and students' temperament type was taken as the moderating variable. Among them, the temperament is divided into five categories: mucous, choleric, depressive, sanguine and hybrid. The hybrid temperament type was used as the reference group.
(1) $\mathrm{Y}$ is regression to $\mathrm{X}$ and $\mathrm{M}$, and the $\mathrm{X}$ coefficient is significant

In the regression coefficient table, the regression results of utility of data content, utility of interaction, autonomy and learning effect are $0.000,0.000$ and 0.000 respectively, all of which are significant at the level of 0.05 .

(2) $\mathrm{W}$ regresses $\mathrm{X}$ and $\mathrm{M}$, and the $\mathrm{X}$ coefficient is significant

The regression results of data content utility, interaction utility and course satisfaction are 0.000 , 0.000 and 0.079 , respectively, which are significant at the level of 0.05 . The regression results of autonomy and course satisfaction are 0.079 , which are significant at the level of 0.1.

(3) $\mathrm{Y}$ regression to $\mathrm{X}, \mathrm{M}, \mathrm{W}$, the $\mathrm{W}$ coefficient is significant

The regression results of utility of data content, utility of interaction, autonomy and learning effect were $0.000,0.000$ and 0.001 , respectively, which were all significant at 0.05 level. The standardized regression coefficient of course satisfaction and learning effect is 0.490 , and the significance is 0.000 , which is significant at the level of 0.05 .

The coefficients of all variables in the above three steps were significant at the level of 0.1 or 0.05 (for one step, the $\mathrm{X}$ coefficient was significant; In the second step, the $\mathrm{X}$ coefficient is significant.), which indicates that course satisfaction has a significant mediating effect, that is, course satisfaction plays a mediating role between the three independent variables and learning effect, which is verified by Hypothesis $\mathrm{H} 2$.

(4) $\mathrm{Y}$ is regression to $\mathrm{X}, \mathrm{M}, \mathrm{W}$ and $\mathrm{MW}$, and the coefficient of MW is significant

The regression results of content utility, interaction utility, autonomy and learning effect were 0.000, 0.000 and 0.000 , respectively, which were all significant at the level of 0.05 .

In the product term coefficient of temperament type and course satisfaction, only the interaction term coefficient of bile quality and course satisfaction is significant at the level of 0.05 , so the H3B is proved, and the hypotheses of $\mathrm{H} 3 \mathrm{~A}, \mathrm{H} 3 \mathrm{~B}$ and $\mathrm{H} 3 \mathrm{D}$ are not valid. People with choleric temperament have a fast reaction speed and higher responsiveness and initiative. Therefore, when people with choleric temperament give a higher degree of satisfaction with the course, the learning effect will be higher. People with choleric types are more likely to have obvious external manifestations, emotions and behavioral movements that occur quickly and intensely: this is why choleric types tend to learn better than people with other temperamental types. 


\subsubsection{Moderating Effect Analysis of Learning Time}

The study duration was divided into two categories: the group with longer study duration above $120 \mathrm{~min}$, and the group with shorter study duration below 120min as the reference group.

There were 638 samples with a learning duration of more than $120 \mathrm{~min}$, accounting for $83.3 \%$, which was a large proportion in the sample structure. The data of this study was surveyed from March to April 2020. During the epidemic period, most schools adopted online courses, and the class schedule was consistent with that in school, so most people had a long learning duration. According to the statistics, the length of study cannot play a regulating role between the independent variable and course satisfaction, so hypothesis $\mathrm{H} 4$ is not valid.

\subsubsection{Moderating Effect Analysis of Teaching Type}

There are two types of teaching: one is the mixed teaching mode of live broadcast and recorded broadcasting, and the other is the single teaching mode of live broadcast or recorded broadcasting.

The results show that compared with the single teaching mode of live broadcast or video broadcast, the interaction utility of the mixed teaching mode of live broadcast and video broadcast has a significant positive effect on course satisfaction, assuming that $\mathrm{H} 5 \mathrm{~B}$ is confirmed, and its moderating effect is completely mediated by course satisfaction. However, the teaching type has no moderating effect on the relationship between the utility of material content, autonomy and course satisfaction, so the hypothesis of H5A and H5D is not valid. Compared with the single teaching mode, live + recorded under the mixed mode of interaction is stronger, the students can in advance through a preview recorded course, find out the difficult points in advance, in the live courses on learning new knowledge, and can interact with the teacher directly, combining two classes after class review summary, and discuss the communication among classmates, the situation of the study effect is better, thus assuming $\mathrm{H} 5 \mathrm{~b}$ was established.

\section{CONCLUSION}

Through multiple linear regression research, it is found that the utility of material content, interaction utility and student autonomy have significant positive influence on the learning effect of online courses. The results show that when the content utility, interaction utility and students' autonomy are high, the students' learning effect is relatively high. The evaluation of course satisfaction mediates the positive effects of content utility, interaction utility and student autonomy on online course learning effect. The temperamental type of individual students has a moderating effect on the correlation between course satisfaction and learning effect, among which the group of choleric type with strong sensibility and rapid change of emotion and behavior has a more prominent moderating effect. To live, recorded, live + recorded in different forms, material content, interactive utility for curriculum, student autonomy level satisfaction evaluation regulation, the online course was recorded using live + mixed teaching mode (compared to live/recorded a single teaching mode), course evaluation level of satisfaction is higher.

In the theoretical sense, this study, based on the interactive influence distance theory, explores the relevant factors that affect the learning effect of online courses. This paper specifically studies the relationship between the content utility of online course materials, the interaction utility between students and content, the interaction utility between teachers and students and students, attention, autonomy and learning effect, the mechanism of different teaching types and length of online courses, and the influence of satisfaction evaluation on learning online courses.

To a certain extent, this research result can expand the relevant research on the learning effect of online courses and supplement the influence mechanism of different course characteristics and students' characteristics and relevant theoretical research. In a practical sense, for students, they can understand the fundamental factors and specific influencing relationships that affect their learning effect, which is conducive to improving their learning effect and weakening the negative effects of adverse factors and habits. For schools, the targeted research results of this study are helpful to improve the effectiveness of research design of online courses, and achieve differentiated teaching models by promoting or restricting certain factors. For online course platform enterprises, corresponding manipulation strategies can be adopted to improve user satisfaction and expand the market scale.

\subsection{Suggestions}

(1) Optimize the design of online course content and auxiliary materials

Optimize the structure design and content arrangement of online courses to ensure the richness of course content. The course structure design should be flexible, and timely adjustment should be made according to the needs of students to ensure the timeliness, accuracy and richness of course videos. Set different learning modes before, during and after class, which can be adjusted and watched at any time. On the basis of the core knowledge structure, interesting and 
extended auxiliary materials are added to stimulate students' exploration consciousness and thirst for knowledge.

\section{(2) Strengthen tripartite online interaction}

In addition to live and recorded courses, learning tasks, sign-in mechanism and group scoring mechanism should be effectively used. Teachers should timely stimulate learners' interest and enthusiasm, give appropriate encouragement and affirmation, guide students to explore problems and transform them into the main body of online courses, so as to make the connection between each other more close. Mobilizing the classroom enthusiasm and improving the classroom atmosphere have a great impact on the course effect. Both teachers and students should abandon the traditional concept of learning and interact deeply and efficiently. Students should also be fully engaged in the course, have the courage to express their views and communicate effectively through interaction, and bring out the true value of online learning.

(3) Stimulate students' autonomy

The effect of online learning depends on the autonomy of students to a certain extent, so it is necessary to strengthen the cultivation of college students' autonomous learning ability and transform the conferred teaching mode into guided teaching mode. In the study of online courses, students with strong autonomy have higher satisfaction evaluation and learning effect on the course, while students with poor autonomy only feel higher satisfaction of the course, but their learning effect has not been effectively improved. This requires the supervision and guidance function of the online course platform to be more perfect, and the lecturers need to take into account the learning performance of more students.

\section{(4) Adjust the teaching mode based on reality}

Based on the learning characteristics of course types, differentiated teaching mode is realized. Students can only receive and transform the course content in a limited way, and it is impossible to achieve efficient individual and group interaction only in the way of recording. Therefore, the corresponding course content in the form of broadcast and recording can be reasonably optimized, aiming to improve the school effect of college students. Use data analysis techniques. Combined with the characteristics of courses and students, the content ratio of different teaching forms is calculated to realize multi-path synchronous learning.

\subsection{Limitations and Prospects}

This study still has the following shortcomings: incomplete sample selection. All samples in this study are from undergraduate students. The research method is simple. This research is limited by practical conditions, Universities in the $5 \mathrm{G}$ Era [J]. Journal of Library Science, 2020(1): 9-12. (in Chinese)
In the future, online experiments with big data can be used to strengthen the validity of the model. In the future, high learning level, niche course learners, skill course learners, on-the-job learners and other groups will be introduced to construct the model. Through more scientific and effective data to carry out experimental research, using different manipulation methods to increase the future operation of the enterprise. Explore the interaction between students' temperament type and other related variables.

\section{REFERENCES}

[1] Baars M., Leopold C., Paas F. 2018. Self-explaining steps in problem-solving tasks to improve self-regulation in secondary education[J]. Journal of Educational Psychology, 110: 578-595.

[2] Baldwin S., Ching Y. H., Hsu Y. C. 2018. Online course design in Higher Education: A review of national and statewide evaluation instruments[J]. TechTrends: Linking Research \& Practice to Improve Learning, 62(1): 46-57.

[3] Jennifer Quong, Sharla L. Snider, Jody Early. 2018. Reducing Transactional Distance in Online and Blended Courses Through the Use of a Closed Social Media Platform[J]. Journal of Educational Technology Systems, 47(1): 79-100.

[4] Lu Huang, Xinning Pei, Yingxi Zhu.2020. A new exploration on the evaluation index system of online course content quality -- based on the perspective of learner experience and knowledge payment [J]. Journal of Distance Education, 38(01): 104-112.

[5] Moore M. G. 1989. Three types of interaction[J]. The American Journal of Distance Education, 3(2): 1-6.

[6] Pingault J B, Tremblay R E, Vitaro F, et al. Childhood trajectories of inattention and hyperactivity and prediction of educational attainment in early adulthood: a 16-year longitudinal population-based study[J]. American Journal of Psychiatry, 2011, 168(11): 1164-1170.

[7] Weiwei Wang. 2020. An Analysis of The Factors Influencing the Interaction Between Teachers and Students in College English Class and The Countermeasures $[\mathrm{J}]$. International Journal of Education and Economics, 3(3): 218-219.

[8] Yingying Li, Hongmei Zhang, Haizhou Zhang.2020. Model construction and empirical test of college students' satisfaction with online learning during the epidemic period: Based on the survey of 15 universities in Shanghai [J]. Open Education Research, (04): 102-111.

[9] Zhang Na. 2020. On Cultivating Learning Autonomy of English Major Students in China[J]. Education Journal, 9(2): 43-47. 